\title{
Capsule Commentary on Nixon et al., Describing Failure in a Clinical Clerkship: Implications for Identifying, Assessing and Remediating Struggling Learners
}

\author{
Patrick Rendón, MD FACP \\ Division of Hospital Medicine, University of New Mexico School of Medicine, Albuquerque, NM, USA.
}

J Gen Intern Med 31(10): 1218

DOI: $10.1007 /$ s11606-016-3778-Z

(c) Society of General Internal Medicine 2016

$\mathrm{F}$ or some time, medical educators have sought the most robust method of identifying and successfully remediating struggling learners. In the study by Nixon et al., the authors conducted an in depth assessment of the reasons for failure within an internal medicine clerkship. ${ }^{1}$ They examined various critical deficiencies and the frequency of those deficiencies across multiple domains: knowledge for practice, interpersonal and communication skills, overall knowledge and skill, patient care, personal and professional development, professionalism, practice-based learning and improvement, interprofessional collaboration, systems-based practice and overall conduct. All students who failed had deficiencies in at least two competency domains, with the most frequently noted critical deficiencies being interpersonal and communication skills, insufficient knowledge and patient care. ${ }^{1}$ Findings were similar in a study of remediating learners and practicing physicians by Guerrasio et al., where subjects were found to have more than one deficit. ${ }^{2}$

Medical educators may then ask the very practical question, "how do educators identify such students?" The authors submit that direct observation and a thorough assessment of medical students in the aforementioned competency domains are key in identifying such deficiencies. Thus, a model of direct observation to identify and remediate failing students could be essential, especially given the underutilization of direct observation that occurs on clerkships. ${ }^{3}$ The authors propose that once a student is identified as failing to meet expectations in one area, this should prompt an examination of competencies in other areas. Effective identification of the struggling learner will allow educators to design a remediation program of a proactive nature. A proposed model of remediation was suggested in a thematic review by Hauer et al., which includes development of a learning plan that integrates deliberate practice, feedback, reflection and reassessment. ${ }^{4}$

Although many questions remain in the search to determine the best approach to struggling learners, this study sets the stage for future research, which should examine methods to improve identification and remediation of medical students.

Corresponding Author: Patrick Rendón, MD FACP; Division of Hospital Medicine University of New Mexico School of Medicine, Albuquerque, NM, USA (e-mail: PRendon@salud.unm.edu).

\section{Compliance with Ethical Standards:}

Conflict of Interest: The author has no conflicts of interest with the material in this article.

\section{REFERENCES}

1. Nixon LJ, Gladding SP, Duffy BL. Describing failure in a clinical clerkship: implications for identifying, assessing and remediating struggling learners. J Gen Intern Med. doi:10.1007/s11606-016-3758-3

2. Guerrasio J, Garrity MJ, Aagaard EM. Learner deficits and academic outcomes of medical students, residents, fellows, and attending physicians referred to a remediation program, 2006-2012. Acad Med. 2014;89:352358.

3. Howley LD, Wilson WG. Direct observation of students during clerkship rotations: A multi-year descriptive study. Acad Med. 2004;79:276-280.

4. Hauer KE, Ciccone A, Henzel TR, Katsufrakis P, Miller SH, Norcross WA, Papadakis MA, Irby DM. Remediation of the deficiencies of physicians across the continuum from medical school to practice: a thematic review of the literature. Acad Med. 2009;84:1822-1832.

Published online June 20, 2016 